\title{
O TEMPO E A(S) MEMÓRIA(S)
}

Elizabeth Wendhausen Rochadel Torresini*

\begin{abstract}
SÍNTESE - Este trabalho trata do tempo, da história e das memórias. Primeiramente, é abordada a construção de uma catedral medieval através de esforços e de suportes coletivos de memória. A seguir, a desestruturação do universo medieval com o desenvolvimento do capitalismo e, por último, o surgimento da história - enquanto tarefa de um historiador profissional - da memória e das memórias.
\end{abstract}

\begin{abstract}
This paper deals with time, history and the memories. First, the building of a medieval cathedral is approached, through the collective efforts and supports of memory. Then, the degeneration of the medieval universe by the development of capitalism and finally, the appearing of history - while the task of . a professional historian - of memory and of memories.
\end{abstract}

\section{1 - A cidade medieval, a catedral e a memória}

A arte das catedrais góticas nasceu com a cidade. O orgulho de habitar uma cidade fazia com que fosse criada, entre as mesmas, uma rivalidade quanto ao tamanho, à beleza e à riqueza que aparecia na catedral.

As corporações, a Igreja, os senhores dos domínios e os seus habitantes contribuiam para a construção de uma igreja, seja através das doações, do trabalho, da engenhosidade, ou do conhecimento e da arte de cada um.

A cidade envolvia-se nessa tarefa desde o transporte das pedras até a criação e colocação dos vitrais, passando por uma extensa variedade de contribuições.

Assim, Paris, Siena, Florença, Colônia, por exemplo, competiam pela altura das torres, pela extensão das naves centrais e pelo colorido dos vitrais.

O mestre-de-obras, mestre construtor ou mestre pedreiro, responsável pela edificação, acumulava, também, funções de arquiteto e de empreiteiro. Era o principal responsável pelo edifício, embora deixasse aos seus subordinados uma liberdade maior do que é possivel hoje, permitindo-lhes desenvolver idéias pessoais nas esculturas dos capitéis, no cinzelamento da pedra das aberturas, portas e arcos (Upjohn et al, 1987, p. 197).

A construção poderia acontecer durante uma ou mais centenas de anos e, nesse longo tempo, as habilidades do mestre e de todos os mestres são concretizadas na pedra, na madeira, no vidro, criando um edifício de múltiplas combinações.

A catedral exprime um fervor religioso no arrojo de suas torres, nas flexas, na grandiosidade das esculturas das portadas. Porém, ela é de responsabilidade do

Pontifícia Universidade Católica do Rio Grande do Sul, PUCRS.

\begin{tabular}{|l|l|l|l|l|l|}
\hline VERITAS & Porto Alegre & v. 41 & $\mathrm{n}^{2} 162$ & Junho 1996 & p. 349-354 \\
\hline
\end{tabular}


mundo secular. A construção dependia da doação da pedreira, de madeiras, jóias, moedas de ouro e prata, coordenadas pelo bispo e pela comunidade.

Dependia de operários que extraíam, serravam e cortavam as pedras e do transporte difícil para o local da construção. Eram construídas carroças e barcos, o alicerce marcado, as árvores derrubadas para a parte principal do edifício, para as escadas e roldanas.

O mestre-de-obras supervisionava o trabalho dos operários, pedreiros, dos transportadores e do madeireiro. Observava, também, o trabalho do mestre canteiro que na sua arte de cantaria escolhia os melhores blocos para cada finalidade. Coordenava a atividade do talhador, dos escultores, dos entalhadores, dos preparadores de argamassa, dos carpinteiros, dos cinzeladores, dos ferreiros, dos encanadores, dos sopradores de vidro, dos vidraceiros, dos forjadores, dos misturadores de tintas e dos telhadeiros.

As mulheres ocupavam-se em armazenar alimentos, cozinhar, fiar e tecer. Todos necessitavam de comida e de vestuário.

As crianças iniciavam-se na arte de aprender através da observação para adquirir uma profissão. Uma catedral era uma escola e os habitantes de uma região sabiam que onde houvesse uma construção haveria trabalho para eles, para seus filhos, netos e bisnetos.

A construção envolvia indiretamente toda a comunidade que plantava, colhia, armazenava, fiava, tecia em função da catedral e da sua própria sobrevivência.

Este mundo é organizado através do uso da memória. Há a memória do mestre-de-obras, do escultor, do cinzelador, do vidraceiro, dos sopradores, dos monjes, das mulheres, dos anciãos que organizavam o repertório de conhecimentos, sem os quais a catedral não existiria.

Assim, passado, presente e futuro - o tempo - estão condensados na igreja que se faz memória e é feita por ela.

A sociedade medieval, aqui descrita intencionalmente semªs suas tragédias e contradições, tem um pólo de identificação popular, que depende da integração consciente e inconsciente das mensagens expressas na catedral.

Esse pólo de identificação combinava-se com outro pólo: o da cultura culta expressa na ação dos mestres e dos monjes.

Os homens, através das doações de bens, de trabalho, num esforço conjunto e amparados por um pólo de identidade, ergueram monumentos que funcionavam, ainda na construção, como centros de memória, como comunidade de sentidos, onde os signos podiam operar.

Seria possivel construir coletivamente nos dias de hoje uma catedral gótica?

Certamente a resposta é não. Mas, se hoje não é possível edificar coletivamente uma catedral do tipo medieval, em que momento e por que as comunidades perderam a sua capacidade de construir através do trabalho coletivizado?

2 - Entro, então, na segunda parte da exposição e respondo: o que minou essa cultura, que respondia pelos empreendimentos coletivos assentes na memória, foi o capitalismo que, ao deslocar populações, rompeu com antigos sistemas e instalou uma desconhecida heterogeneidade. Criou a economia de mercado, a máqui- 
na, uma nova divisão social do trabalho, a cultura burguesa com outros códigos e novas formas de produção.

Diante dessas transformações, Max Weber propõe uma diferença entre a conduta não capitalista e a capitalista:

\begin{abstract}
"um elemento central do capitalismo fundamenta-se numa modalidade de razão dirigida. Seu racionalismo se apóia no desenvolvimento das operações contábeis, abrangendo todos os escalões da esfera dos negócios, pois a racionalização da contabilidade é o pressuposto do equilibrio de uma empresa qualquer. Trata-se, por conseguinte, de uma razão dirigida a certa meta, de natureza econômica, e que provoca o reagenciamento de todos os fatores interligados - mão-de-obra, base técnica, escolha de matéria-prima, capital aplicado e sua volta multiplicada - com o fito que permanece basicamente econômico (Max Weber apud Costa Lima, 1982, .35). ${ }^{1}$
\end{abstract}

Até o século XIX, o capitalismo produziu efeitos inesperados na Europa. Um deles foi o deslocamento irreversível de massas humanas do campo e da cidade medieval para os novos locais de produção.

As populações que tinham o mundo da sua vida regulado por um determinado pólo de identificação, são jogadas nas novas cidades - burguesas - sem ter acesso a um segundo pólo de identificação que é o da cultura escolarizada, regida por outros códigos (Costa Lima, 1982, p. 37). Esses códigos eram diferentes daqueles que permitiam, por exemplo, a união em torno da construção de uma catedral.

Na cidade do progresso, que Walter Benjamin tanto analisou, homens, mulheres e crianças trocam seu trabalho por salários. Não existe a catedral socialmene construida, o artesanato, a narração da experiência. Existem distâncias.

Assim, para que a nova cidade funcione é preciso criar um pólo de entendimento geral, que seja público e não especializado.

Um entendimento promovido por intelectuais, elaborado numa linguagem adaptada ao consumo de um público que ainda não conhece bem o que acontece a sua volta.

Nasce, então, uma cultura síntese do pólo tradicional das sociedades pré-industriais e do pólo moderno da nova cidade.

Um exemplo dessa síntese é o aparecimento do romance e do romancista, dos grandes jornais, almanaques; novelas em série, cartazes e fotografias que indicam um esforço de se estabelecer o entendimento geral.

3 - Afirmo, na terceira parte dessa exposição, que é justamente nesse universo que a atividade de historiar o passado passa a ser uma tarefa profissional feita por historiadores e que exige algum método.

O historiador apresenta-se à sociedade como um leitor especializado do mundo, da totalidade, do real. Ele é um leitor especializado do passado comum das coletividades.

Como o mundo não é mais o das catedrais, nem de fácil sustentação de heróis exemplares, o historiador encarrega-se de olhar para o passado e lá identificar a

1 Essa racionalização empresarial dependeu de um forte desenvolvimento da tecnologia no século XX, que forneceu ó suporte para a expansão da economia de mercado. 
origem das nações que se organizam, além de seus fatos importantes e feitos famosos.

O historiador do século XIX busca nas fontes documentais o passado comum. As fontes falam e contam uma história; é tarefa do historiador transformá-la em livros para poder aproximar-se de seu público. O fazer história transforma-se num ofício, numa profissão que é desempenhada por determinados indivíduos da sociedade.

Ainda no século XIX, mais propriamente depois da publicação da História dos povos latinos e germânicos (1824) de Leopold Von Ranke, a história propõe-se a criar explicações com base em sólido material empírico assegurado por técnicas e metodologias de pesquisa. São criadas as cadeiras de História nas faculdades, introduzidas disciplinas nos currículos escolares, organizados arquivos, fundadas instituições (institutos históricos e geográficos) e lançadas revistas especializadas. É construído o mundo dos historiadores (Pereira das Neves, 1984, p. 21).

O surgimento da história como um ofício deve ser também explicado, como nos diz Arnold Hauser, pela aceitação da atitude romântica no século XIX. Os românticos fazem da história uma preciosa fonte de inspiração.

"Só a partir da Revolução (Francesa) e do movimento romântico é que a natureza do homem e da sociedade começou a ser considerada essencialmente dinâmica" (p. 822). "A visão de que existe realmente um destino histórico e de que nós somos exatamente 0 que somos, porque consideramos retrospectivamente uma espécie particular de história passada é uma conquista do romantismo. [...] A idéia de que a natureza do espirito humano, das instituições políticas, da lei, linguagem, religião e arte só se pode compreender, fundamentando-nos na sua história, e que a vida representa a esfera em que estas estruturas encarnam na forma mais pura e substancial, teria sido absolutamente inconcebivel antes do romantismo" (Hauser, 1972, p. 823).

A valorização da nação, dos heróis e do fato histórico significou a exaltação de uma nova visão de mundo que transforma a História numa longa marcha em direção ao progresso, à liberdade, à ciência, ao bem-estar e à paz social. Os fatos, porém, são únicos e irrepetíveis. São singularidades que só acontecem uma vez e que produzem identidades particulares.

Essa história conhecida como história narrativa, empiricista, positivista, pode ser, em alguns casos, chamada de história oficial, porque cria um passado único, uma única memória. Cria a memória nacional que é a memória oficial.

Edgar De Decca ao tratar da historiografia do século XIX, faz um balanço positivo ao afirmar que "a história, memorizando o passado como identidade da nação, preencheu 0 antigo lugar ocupado pela memória coletiva nas sociedades pré-industriais, tornando-se o discurso legitimador dos símbolos trazidos de um passado longínquo e que serviram de suportes para a afirmação do povo-nação" (p. 135).

Porém, a História não deve produzir uma única versão dos fatos. As possibilidades de interpretação histórica e de resgate do real passado são múltiplas.

A respeito dessa multiplicidade, Marilena Chaú diz que todos somos memoriosos e memorialistas.

"A memória, seja como história da sociedade, seja como crônica das classes sociais e de seus homens ilustres, tem o papel de nos liberar do passado como fantasma, como fardo, como assombração e como repetição. [...] Uma compreensão política da memória é atenta à diferença temporal entre o passado e o présente, é atenta à diferença das memórias sociais 
que constituem o presente, é atenta à necessidade de liberar a memória e de explicitá-la para que o presente se compreenda a si mesmo e possa construir/inventar o futuro" (Chaui, 1992, p. 43).

Como memoriosos, somos capazes de criar e recriar nosso passado individual quantas vezes forem necessárias para a compreensão ou explicitação do mesmo. Somos capazes de lembrar, de rememorar.

Como memorialistas, todos somos capazes de dar sentido a uma trama, a um fato, e esclarecê-lo através de algumas concepções do presente. Como memorialistas fazemos o registro da memória.

Nessa perspectiva, os historiadores são os memorialistas por profissão que fazem do material histórico o resultado das suas reflexões sobre a vida dos seres humanos em sociedade, de suas relações com o natural e o sobrenatural. As dimensões desses fenômenos históricos são tantas que hoje não se acredita mais numa única versão da História, portanto numa única prática historiográfica.

A nossa sociedade, desde que foram perdidos os pólos de identificação tradicionais, tem escolhido a produção memorialista dos historiadores como um pólo de identificação de memórias. É através da atuação constante dos historiadores que novos lugares de memória são construídos, com uma ampla participação de alguns setores da sociedade, temerosos da própria perda da memória coletiva como um fenômeno típico da época em que se vive.

O desejo de arquivar, verdadeira obsessão das sociedades contemporâneas, parece animar todos os grupos e indivíduos. No afã de registrar, nós não vivemos os rituais. Nós os filmamos, não desfrutamos das paisagens, das viagens, nós as fotografamos. Nas solenidades e nos encontros as filmadoras e câmeras fotográficas ganham mais importância do que o próprio ritual. Basta registrar, guardar uma memória para que a ordenação das vidas se torne um fato concreto.

Todo esse desejo de registro tem como resultado a construção de uma memória que descansa num padrão de cristalização do passado. O passado como mero documento é memória que nada diz, ou diz muito pouco, porque não analisa, não explica e interpreta o que aconteceu. A memória única não cria contradição e não permite as visões múltiplas do que aconteceu.

Defende-se, por isso, a idéia de que a tarefa primeira do historiador é a de abrir o passado para apontar as diferenças e semelhanças, as permanências e variações dos padrões de estrutura social; examinar e explicar as rupturas e as desigualdades sociais, além do levantamento de todo o universo dos acontecimentos e dos fatos propriamente ditos.

A historiografia contemporânea tem optado pela convivência de diferentes metodologias e pela produção de um saber que se revela em memórias e não numa única e irrefutável memória. Os historiadores, em nome do exposto, tendem a conviver com a reescrita constante da História.

Assim, é possivel tecer e retecer o acontecido. Quando alguém diz "essa é a história dos trabalhadores", imediatamente pode defrontar-se com uma história desses trabalhadores organizada por outro profissional, a partir de outros pressupostos, e com resultados diferentes.

A História pode nos apresentar alternativas. Pode nos lembrar de que assim como a Natureza, nos seus processos de interação, depende da fauna, da flora, dos 
ventos, dos rios e dos mares, nós, na nossa Humanidade, não podemos evitar a multiplicidade, o heterogêneo e o plural.

Não podemos criar uma única memória, nem como memoriosos e, tampouco, como memorialistas. Devemos trabalhar no sentido de termos muitas memórias como memoriosos e como memorialistas que somos, posto que essa capacidade nos é inerente.

\section{Referências bibliográficas}

CHAUf, Marilena. Politica Cultural, cultura politica e patrimônio histórico. São Paulo (cidade). Departamento de Patrimônio Histórico. O direito à memória: patrimônio histórico e cidadania/DPH, 1992.

COSTA LIMA, Luiz. "Comunicação e cultura de massa. In: - — - Teoria da cultura de massa. 3. ed. Rio de Janeiro: Paz e Terra, 1982.

DE DECCA, Edgar S. Memória e cidadania. São Paulo (cidade). Departamento de Patrimônio Histórico. O direito à memória: patrimônio histórico e cidadania/DPH, 1992.

HAUSER, Arnold. História social da literatura e da arte. São Paulo: Mestre Jou, 1972. T. II.

PEREIRA DAS NEVES, Guilherme. "História: a polissemia de uma palavra". Porto Alegre, Estudos IberoAmericanos, v. X, n. 1, julho de 1984.

UPJOHNm, Everard et al. História mundial da arte. 8. ed. Lisboa: Bertrand, 1987. v. 2. 